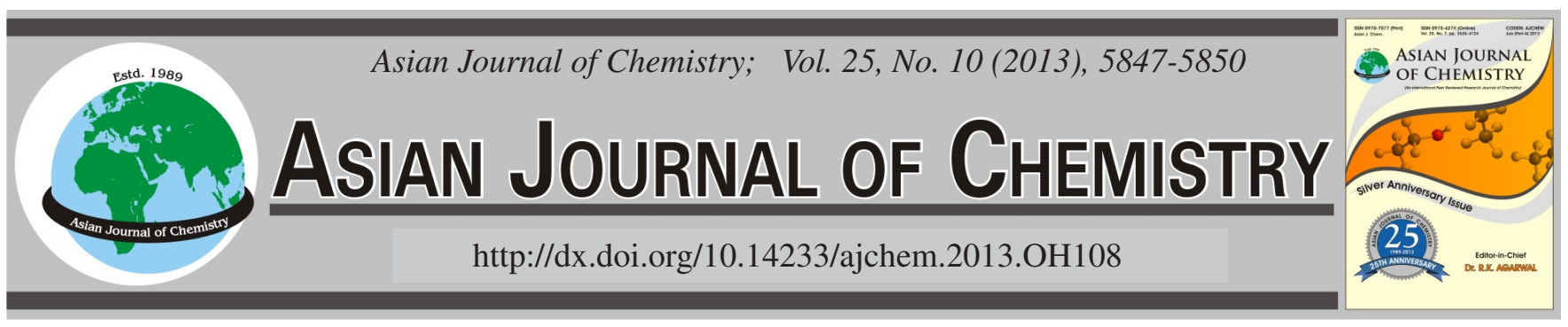

\title{
Characterization of Hydroxyapatite Nanoparticles from Fish Scale Waste and Its Adsorption of Carotenoids $\dagger$
}

\begin{abstract}
Supalak Kongsri ${ }^{1}$, Pattarapond Ladawan Na Ayuttaya ${ }^{1}$, Sorasart Yookhum ${ }^{1}$, Suchila Techawongstein ${ }^{2}$ and Saksit Chanthai ${ }^{1 \text {,* }}$
${ }^{1}$ Department of Chemistry and Center for Innovation in Chemistry, Faculty of Science, Khon Kaen University, Khon Kaen 40002, Thailand ${ }^{2}$ Department of Plant Science and Agricultural Resources, Faculty of Agriculture, Khon Kaen University, Khon Kaen 40002, Thailand
\end{abstract}

*Corresponding author: E-mail: sakcha2@kku.ac.th

AJC-13351

\begin{abstract}
Hydroxyapatite nanoparticles (FHAp) of fish scales were prepared by alkaline heat treatment method. Chemical structure, morphology and thermal property of solid powder obtained were characterized by surface analysis, X-ray diffraction and Fourier transform infrared spectroscopy, scanning electron microscopy and thermal analysis in comparison with those of chitosan. The results showed that the nanosized particles of hydroxyapatite nanoparticles have high porosity and surface roughness. In application, the potential use of hydroxyapatite nanoparticles as adsorbent for $\beta$-carotene/lycopene from tomato extract was investigated under optimized conditions. The adsorption isotherms demonstrated that the adsorption behaviours of the carotenoids on both hydroxyapatite nanoparticles and chitosan substrates were well fitted with both of Langmuir and Freundlich isotherms. However, difference in sensitivity and selectivity of its hydrophobic interactions of the conjugated alkene molecule to the ionic surface of hydroxyapatite nanoparticles was somewhat pronounced comparing with chitosan.
\end{abstract}

Key Words: Hydroxyapatite, Fish scale, $\beta$-Carotene, Lycopene, Adsorption isotherm.

\section{INTRODUCTION}

Numerous studies have recognized that the adsorption ability of hydroxyapatite (HAp), $\mathrm{Ca}_{10}\left(\mathrm{PO}_{4}\right)_{6}(\mathrm{OH})$ has recently been attracted considerable interest as sorbents in the purification of wastewater. Natural hydroxyapatite resources, e.g. fish scales ${ }^{1}$, natural apatite minerals ${ }^{2}$, synthetic hydroxyapatites prepared by sintering or other calcium phosphates like monetite and brushite ${ }^{3,5}$ have been developed by various methods. The cost of synthetic hydroxyapatite is very expensive due to the use of high purity reagents. The hydroxyapatite from fish scales inherits such chemical property that can be produced by simple and inexpensive method. Its chemical composition is mostly in the same empirical form of teeth and bone ${ }^{5,6}$. They are important sources of the natural hydroxyapatites, which could be high value-added products in manufacturing functional foods, drug delivery systems, biomaterials and biomedical products ${ }^{7}$.

\section{EXPERIMENTAL}

Fish (Tilapia nilotica) scale waste was soaked and washed thoroughly in distilled water and left air dry. At first, it was treated with $0.1 \mathrm{M} \mathrm{HCl}$ for $2 \mathrm{~h}$ at room temperature and then washed thoroughly several times with distilled water. The fish scale was treated with $5 \%$ (w/v) $\mathrm{NaOH}$ at $70{ }^{\circ} \mathrm{C}$ for $5 \mathrm{~h}$ with gentle stirring to eliminate all proteins attached with the scales. The obtained white precipitate was washed several times with distilled water, until $\mathrm{pH}$ of the washing solution became neutral and dried at $60{ }^{\circ} \mathrm{C}$ for $48 \mathrm{~h}$. Next, $50 \%$ (w/v) $\mathrm{NaOH}$ was added into the treated scale powder, heated with stirring up to $100{ }^{\circ} \mathrm{C}$ for $1 \mathrm{~h}$. The precipitated product was finally rinsed with deionized water until appearance of the neutral $\mathrm{pH}$ of the rinsed solution and dried at $60{ }^{\circ} \mathrm{C}$ for $24 \mathrm{~h}$ prior to use.

Characterization of the hydroxyapatite nanoparticles were conducted by various chemical, physical and spectroscopic techniques including $\mathrm{Ca}$ and $\mathrm{P}$ ratio, surface area analysis, $\mathrm{X}$-ray diffraction, Fourier transform infrared spectroscopy, scanning electron microscope and thermal analysis.

Adsorption study: For batch adsorption, adsorbents ( 0.10 g) were accurately weighed into $125 \mathrm{~mL}$ conical flask. Then, $20 \mathrm{~mL}$ of the carotenoids extract from tomato $(10 \mathrm{mg} / \mathrm{L})$ was added and $\mathrm{pH}$ of the mixture was adjusted and shaken by an orbital shaker at approximately $250 \mathrm{rpm}$ for $6 \mathrm{~h}$ at ambient temperature $\left(30^{\circ} \mathrm{C}\right)$. Various experimental parameters were studied including the effects of $\mathrm{pH}$, an adsorbent dosage, an 
initial concentration, ionic strength, surfactant and a contact time. After a period of shaking, the adsorbents were separated from the solutions by filtering with Whatman filter paper No. 42 . The concentration of $\beta$-carotene and lycopene in the filtrate was determined by UV-visible spectrophotometer at 450 and $470 \mathrm{~nm}$, respectively.

The adsorption capacity $\left(\mathrm{q}_{\mathrm{e}}, \mathrm{mg} / \mathrm{g}\right)$ of both carotenoids at an equilibrium state was determined using $\mathrm{q}_{\mathrm{e}}=\mathrm{V}\left(\mathrm{C}_{\mathrm{o}}-\mathrm{C}_{\mathrm{e}}\right) / \mathrm{m}$. Where $\mathrm{C}_{\mathrm{o}}$ is an initial concentration $(\mathrm{mg} / \mathrm{L})$ of carotenoids, $\mathrm{C}_{\mathrm{e}}$ is concentration $(\mathrm{mg} / \mathrm{L})$ of each carotenoids at equilibrium state, $\mathrm{V}$ is volume $(\mathrm{mL})$ of the solution and $\mathrm{m}$ is mass $(\mathrm{g})$ of the adsorbent. Briefly, for Langmuir adsorption isotherm ${ }^{8} ; \mathrm{q}_{\mathrm{e}}$ $=\mathrm{q}_{\max } \mathrm{bC}_{\mathrm{e}} /\left(1+\mathrm{bC}_{\mathrm{e}}\right)$ or $1 / \mathrm{q}_{\mathrm{e}}=1 / \mathrm{q}_{\max }+1 / \mathrm{bC}_{\mathrm{e}} \mathrm{q}_{\max }$. When plotting $1 / \mathrm{q}_{\mathrm{e}} v s .1 / \mathrm{C}_{\mathrm{e}}$ will give a linear curve with slope of $\mathrm{K}_{\mathrm{L}}=1 / \mathrm{b} \mathrm{q}_{\max }$ and intercept of $1 / \mathrm{q}_{\max }$.

The Freundlich equation ${ }^{9}$ used for an isothermal adsorption is also a special case for heterogeneous surface. As for $\mathrm{q}_{\mathrm{e}}=\mathrm{K}_{\mathrm{F}} \mathrm{C}_{\mathrm{e}}^{(1 / \mathrm{n})}$, plotting $\ln \mathrm{q}_{\mathrm{e}}=\ln \mathrm{K}_{\mathrm{F}}+1 / \mathrm{n} \ln \mathrm{C}_{\mathrm{e}}$ will give a linear curve with slope of $n$ and intercept of $\mathrm{K}_{\mathrm{F}}$. Giving, $\mathrm{K}_{\mathrm{F}}$ and $\mathrm{n}$ are the Freundlich constants indicating adsorption capacity (mg/ g) and intensity, respectively. The Freundlich exponent of $1 / n$ indicates the favourability of the adsorption, surface heterogeneity and surface affinity for the solute. If higher value of $1 / \mathrm{n}$ is obtained, it will correspond to the greater heterogeneity of the adsorbent surface.

\section{RESULTS AND DISCUSSION}

In this study, the fish (Tilapia nilotica) scales were pretreated with dilute hydrochloric acid and then treated with alkaline heat treatment method, resulting in nano-size material of fish hydroxyapatite. The $\mathrm{Ca} / \mathrm{P}$ molar ratio of hydroxyapatite nanoparticles powder according to energy dispersive (TEMEDX) spectrum was about 1.66 that slightly lower than the theoretical value (1.67). The XRD pattern of hydroxyapatite nanoparticles matches well with that of commercial hydroxyapatite, confirming that the material derived from the fish scales was very close to the apatite structure. The broaden peaks of XRD data of commercial hydroxyapatite indicate low crystallinity while those of hydroxyapatite nanoparticles are sharper but still be amorphous. The major characteristic peaks of hydroxyapatite nanoparticles was obtained at 25.9, 31.8, 32.2, $34.1,40.0$ and $46.7^{\circ}$ at which were assigned to (002), (211), (112), (202), (310) and (222) indices, respectively (data not shown). The estimated crystal size of hydroxyapatite nanoparticles as calculated by Scherrer equation ${ }^{10}$ was $21 \mathrm{~nm}$. From SEM micrograph (Fig. 1), it is shown that the nanoparticles of hydroxyapatite nanoparticles were formed having pores distributed over its surface.

The specific surface areas of hydroxyapatite nanoparticles and its fish scale compared with chitosan extracted from prawn were obtained (Table-1) by BET and Langmuir methods. We compared its physical property with chitosan from prawn because the nature sheet of both fish scale and prawn scale were soft and thin rigidity, even its composition was found differently between organic and inorganic materials. From the results, the physical characteristics of the hydroxyapatite nanoparticles are fine particles with larger specific surface area and pore volume. This property may attribute that the nanoparticles are recognized as a suitable adsorbent for adsorption applications.

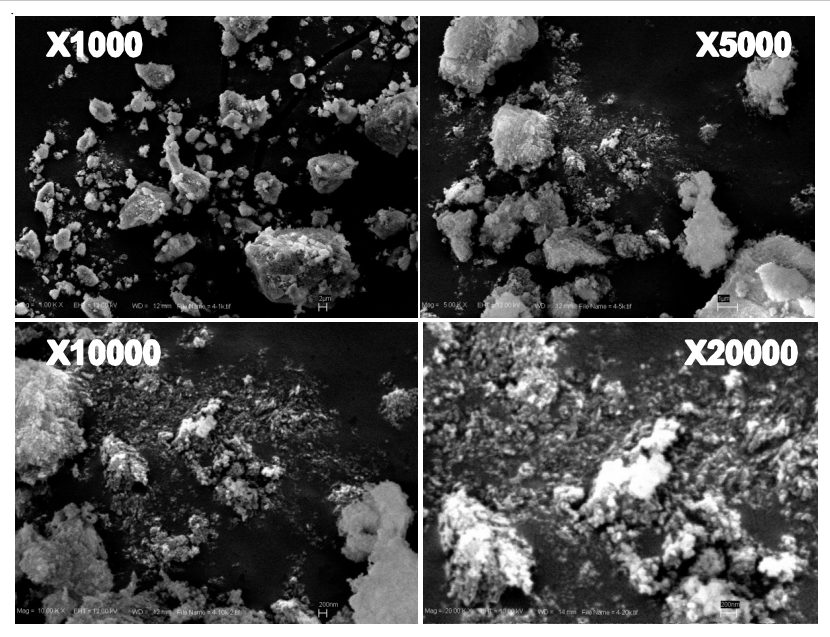

Fig. 1. SEM pictures of hydroxyapatite nanoparticles at different magnifications showing high porosity and surface roughness

\begin{tabular}{lcccc}
\multicolumn{5}{c}{ TABLE-1 } \\
\multicolumn{5}{c}{$\begin{array}{c}\text { SPECIFIC SURFACE AREA OF CHITOSAN, } \\
\text { FISH SCALE AND FHAp SAMPLES }\end{array}$} \\
\hline \multirow{2}{*}{ Sample } & $\begin{array}{c}\text { BET } \\
\text { surface } \\
\text { area }\left(\mathrm{m}^{2} / \mathrm{g}\right)\end{array}$ & $\begin{array}{c}\text { Langmuir } \\
\text { surface } \\
\text { area }\left(\mathrm{m}^{2} / \mathrm{g}\right)\end{array}$ & $\begin{array}{c}\text { Pore } \\
\text { volume } \\
\left(\mathrm{cm}^{3} / \mathrm{g}\right)\end{array}$ & $\begin{array}{c}\text { Average } \\
\text { pore size } \\
(\AA)\end{array}$ \\
\hline Chitosan & 2.26 & 11.43 & 0.0162 & 287.8 \\
Fish scale & 16.6 & 25.9 & 0.0331 & 79.6 \\
FHAp & 125.4 & 183.6 & 0.5017 & 160.0 \\
\hline
\end{tabular}

Thermal analysis of hydroxyapatite nanoparticles was carried out. The total weight loss was found to be $9.24 \%$. According to both TG and DTG curves (data not shown), there are two stages of the mass loss: $50-200{ }^{\circ} \mathrm{C}$ and $600-1000{ }^{\circ} \mathrm{C}$. The first step of the mass loss is reported as the removal of adsorbed water from the surface. The second one starting at a temperature of $700{ }^{\circ} \mathrm{C}$ is related to the following processes including dehydroxylation, decomposition of hydroxyapatite nanoparticles and loss of carbonate groups as confirmed by DTG curves of the second stage of the mass loss, at which correspond to the dehydroxylation and decomposition of the hydroxyapatite nanoparticles due to the release of $\mathrm{OH}$ groups. At this stage, the mass loss is about $2.68 \%$. The mass losses at $200-500^{\circ} \mathrm{C}$, correspond to the removal of organic compounds in fish scales, was not observed in the DTA curve because the organic components of fish scales were removed completely during the sample treatment. The temperature range of dehydroxylation of the hydroxyapatite nanoparticles is 700$1000^{\circ} \mathrm{C}$, which agrees well with the decomposition reactions of hydroxyapatite ${ }^{11}$.

The characteristic absorption of hydroxyapatite nanoparticles were observed in the FTIR spectrum. The FTIR spectrum of hydroxyapatite nanoparticles was almost similar to that of commercial hydroxyapatite (data not shown). The broad band from 3700 to $2500 \mathrm{~cm}^{-1}$, the most intensive peak of hydroxyapatite nanoparticles, is represented the stretching modes of hydrogen bonding of water molecules. Strong bands of phosphate, $\mathrm{PO}_{4}{ }^{3-}$ are found at 1045,1088 and $967 \mathrm{~cm}^{-1}$. In addition, the spectra show the absorption peaks at 873,1415 and $1430 \mathrm{~cm}^{-1}$ which correspond to the vibrations of carbonate, $\mathrm{CO}_{3}{ }^{2-}$ in the structure of hydroxyapatite. However, the $1650 \mathrm{~cm}^{-1}$ band could also be assigned for the carbonate group or water molecule ${ }^{12,13}$. 
Adsorption isotherm: Adsorption isotherms are crucial theory to study because the isotherms describe how adsorbate interacts with adsorbent. Optimum conditions for the adsorption of both carotenoids (using an initial concentration of 10 $\mathrm{mg} / \mathrm{L}$ each of $\beta$-carotene and lycopene crude extracts from tomato sample) were investigated in comparison with the natural polymer chitosan prepared from prawn, since the adsorbent used in this case is charged inorganic salt, $0.1 \mathrm{~g}$ hydroxyapatite nanoparticles and the adsorbate is a non-polar conjugated double bond in the skeletal structure of organic molecule. The effect of $\mathrm{pH}$ on the adsorption study for $24 \mathrm{~h}$ incubation was varied between 3 and 10, resulting in maximum adsorption capacity, $\mathrm{q}_{\mathrm{e}}$, at $\mathrm{pH} 7$ (data not shown). It was found that the $\mathrm{q}_{\mathrm{e}}(\mathrm{mg} / \mathrm{g}$ ) values for lycopene are greater than those of $\beta$-carotene for both hydroxyapatite nanoparticles and chitosan, but the $\mathrm{q}_{75}$ for lycopene/chitosan is found slightly greater than that of lycopene/ hydroxyapatite nanoparticles. It is noted that the interactions between organic compound themselves are still much more pronounced. Regarding on contact time or incubation time of the adsorption equilibrium, which was varied from $3 \mathrm{~h}$ to $24 \mathrm{~h}$ (data not shown), the adsorption equilibrium state expressed as the $\mathrm{q}_{\mathrm{e}}$ value was reached constantly within $9 \mathrm{~h}$ for both couple of lycopene/ $\beta$-carotene on hydroxyapatite nanoparticles and chitosan. The effect of adsorbent dosage for hydroxyapatite nanoparticles and chitosan on percentage of removal of both carotenoids was studied. For both hydroxyapatite nanoparticles and chitosan, \% removal of lycopene is greater than $\beta$-carotene as the dosage varied from $0.025 \mathrm{~g}$ to $0.2 \mathrm{~g}$ (data not shown) at $\mathrm{pH} 7$ with $6 \mathrm{~h}$ and $9 \mathrm{~h}$ contact time for hydroxyapatite nanoparticles and chitosan, respectively, but at $0.1 \mathrm{~g}$ of the adsorbent dosage of chitosan it shows \% removal of both carotenoids greater than that of hydroxyapatite nanoparticles according to the same adsorption behaviour mentioned above.

The effect of an initial concentration of both carotenoids (1.0-17.5 mg/L) in the presence of $0.15 \mathrm{~g}$ adsorbent with other optimized conditions was also carried out. It was found that by using $10 \mathrm{mg} / \mathrm{L}$ of each carotenoids, the $\mathrm{q}_{\mathrm{e}}$ values for $\beta$ carotene on both hydroxyapatite nanoparticles and chitosan are greater than those of lycopene on both hydroxyapatite nanoparticles and chitosan (data not shown). Therefore, it is concluded that, under the optimized conditions, although the adsorption behaviours of both carotenoids on both hydroxyapatite nanoparticles and chitosan were found rather selectively different among organic adsorbate with inorganic sorbent like hydroxyapatite nanoparticles. It is implied that hydroxyapatite material can be a good substrate for adsorption of the carotenoids extracts with significant extents, ascribing any plant pigments carrier in physiological functions and/or its metabolism.

However, in general the detailed adsorption function and stability is defined via adsorption isotherm. Langmuir (Fig. 2 and Table-2) and Freundlich (Fig. 3 and Table-3) models are often used to describe the adsorption isotherms by plotting the data of varying the concentration of the carotenoids.

The $\mathrm{K}_{\mathrm{L}}$ and $\mathrm{K}_{\mathrm{F}}$ obtained from both Langmuir and Freundlich adsorption isotherms, respectively and their regression coefficients $\left(\mathrm{R}^{2}\right)$ were calculated. Based on the $\mathrm{R}^{2}$ obtained, it can be indicated that the Langmuir isotherm with $\mathrm{R}^{2}$ higher than 0.99 was the most proper model to describe the
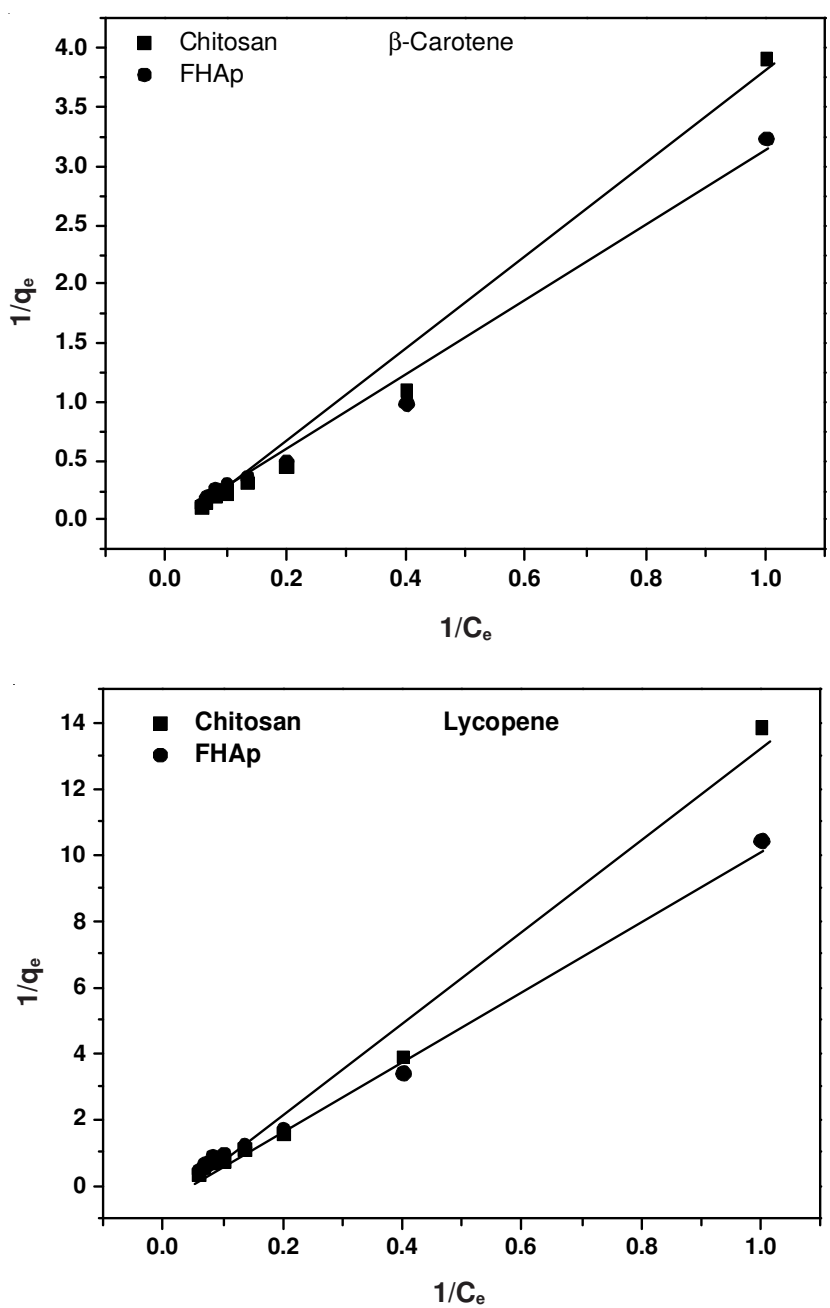

Fig. 2. Langmuir adsorption isotherms for $\beta$-carotene/lycopene adsorption on hydroxyapatite nanoparticles and chitosan

TABLE-2

PARAMETERS AND CORRELATION COEFFICIENT $\left(R^{2}\right)$ FOR LANGMUIR ADSORPTION ISOTHERM

\begin{tabular}{lccc|ccc}
\hline \multirow{3}{*}{ Adsorbent } & \multicolumn{3}{c|}{$\beta$-carotene } & \multicolumn{3}{c}{ Lycopene } \\
\cline { 2 - 7 } & $q_{m}$ & $K_{L}$ & $R^{2}$ & $q_{m}$ & $K_{L}$ & $R^{2}$ \\
& $(\mathrm{mg} / \mathrm{g})$ & $(\mathrm{L} / \mathrm{g})$ & & $(\mathrm{mg} / \mathrm{g})$ & $(\mathrm{L} / \mathrm{g})$ & \\
\hline FHAp & 14.18 & 0.3099 & 0.9900 & 5.93 & 0.0959 & 0.9938 \\
Chitosan & 4.88 & 0.2498 & 0.9872 & 1.35 & 0.0705 & 0.9876 \\
\hline
\end{tabular}

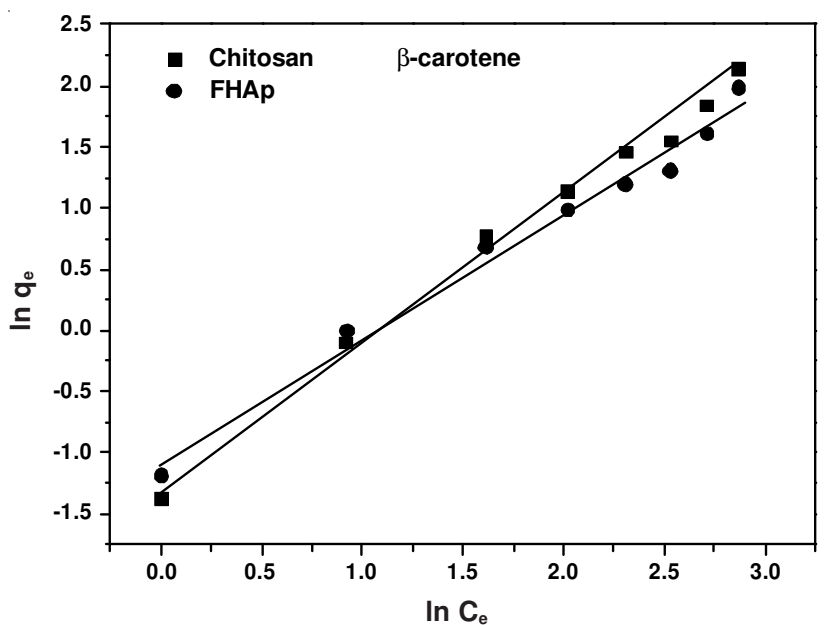




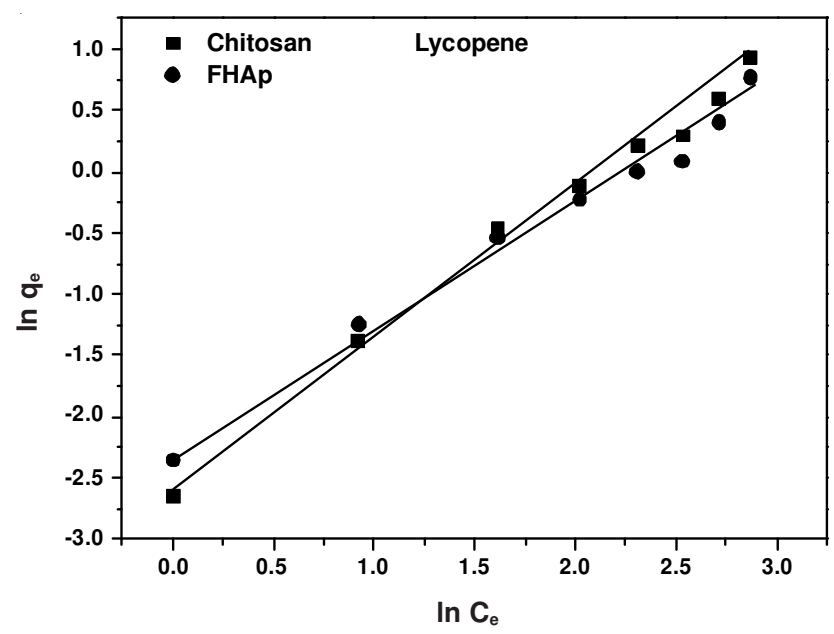

Fig. 3. Freundlich adsorption isotherms for $\beta$-carotene/lycopene adsorption on hydroxyapatite nanoparticles and chitosan

TABLE-3

PARAMETERS AND CORRELATION COEFFICIENT $\left(R^{2}\right)$ FOR FREUNDLICH ADSORPTION ISOTHERM

\begin{tabular}{lcccccc}
\hline \multirow{2}{*}{ Adsorbent } & \multicolumn{3}{c}{$\beta$-carotene } & \multicolumn{3}{c}{ Lycopene } \\
\cline { 2 - 7 } & $n$ & $K_{F}$ & $R^{2}$ & $n$ & $K_{F}$ & $R^{2}$ \\
\hline FHAp & 0.9853 & 1.0631 & 0.9840 & 0.9910 & 2.2631 & 0.9864 \\
Chitosan & 0.8547 & 1.25 & 0.9922 & 0.8444 & 2.5224 & 0.9916 \\
\hline
\end{tabular}

equilibrium adsorption behaviour of the hydroxyapatite nanoparticles. While the adsorption of carotenoids onto chitosan substrate is well fitted by the Freundlich isotherm $\left(\mathrm{R}^{2}>0.99\right)$ compared with the Langmuir isotherm which gives slightly lower $\mathrm{R}^{2}>0.98$.

\section{Conclusion}

Hydroxyapatite nanoparticles from the fish scales could be simply prepared by alkaline heat treatment method. Both FTIR and XRD results confirmed its chemical structure which matched well with those of the commercial hydroxyapatite.
SEM and surface area analysis showed its nano-sized particles and high porosity. It is attributed to the availability of higher surface area of the nanoparticles which enhances surface sorption of the carotenoids. Their adsorption isotherms correlated quite well with both Langmuir and Freundlich adsorption models.

\section{ACKNOWLEDGEMENTS}

This work was supported by the Higher Education Research Promotion and National Research University Project of Thailand, Office of the Higher Education Commission, through the Food and Functional Food Research Cluster of Khon Kaen University. The Center of Excellence for Innovation in Chemistry (PERCHCIC), Commission on Higher Education, Ministry of Education and the Hitachi Scholarship Foundation, Tokyo, Japan, are gratefully acknowledged.

\section{REFERENCES}

1. S. Mondal1, B. Mondal, A. Dey and S.S. Mukhopadhyay, J. Miner. Mater. Character. Eng., 11, 1 (2012).

2. Y.C. Huang, P.C. Hsiao and H.J. Chai, Ceram. Int., 37 (2011).

3. S. Sugiyama, T. Ichii, M. Fujisawa, K. Kawashiro, T. Tomida, N. Shigemoto and H. Hayashi, J. Colloid Interf. Sci., 259 (2003).

4. N. Arnich, M.C. Lanhers, F. Laurensot, R. Podor, A. Montiel and D. Burnel, Environ. Pollut., 124 (2003).

5. W. T. Liu, Y. Zhang, G.Y. Li, Y.Q. Miao and X.H. Wu, J. Fish Biol., 72 (2008).

6. F. Zhang, S. Xu and Z. Wang, Food Bioprod. Process., 89 (2011).

7. J.R. Metz, E. Vrieze, E.J. Lock, I.E. Schulten and G. Flik, J. Appl. Ichthyol., 28 (2012).

8. M. Islam, P.C. Mishra and R. Patel, J. Hazard. Mater, 189 (2011).

9. F. Googerdchian, A. Moheb and R. Emadi, Chem. Eng. J., 200, 202 (2012).

10. C. Suryanarayana and M.G. Norton, X-Ray Diffraction: A Practical Approach, Plenum Press (1998).

11. A.S. Kupiec and Z. Wzorek, Ceram. Int., 38 (2012).

12. M. Markovic, B.O. Fowler and M.S. Tung, J. Res. Nat. Inst. Stand. Technol., 109 (2004).

13. D. Luna-Zaragoza, E.T. Romero-Guzmán and L.R. Reyes-Gutiérrez, J. Miner. Mater. Charact. Eng., 8, 591 (2009). 